\title{
Absolute Ca Isotopic Measurement Using an Improved Double Spike Technique
}

\author{
Jason Jiun-San Shen", Der-Chuen Lee, and Wen-Tzong Liang \\ Institute of Earth Sciences, Academia Sinica, Taipei, Taiwan, ROC
}

Received 5 March 2008, accepted 30 May 2008

\begin{abstract}
A new vector analytical method has been developed in order to obtain the true isotopic composition of the ${ }^{42} \mathrm{Ca}-{ }^{48} \mathrm{Ca}$ double spike. This is achieved by using two different sample-spike mixtures combined with the double spike and natural $\mathrm{Ca}$ data. Because the natural sample (two mixtures) and the spike should all lie on a single mixing line, we are able to constrain the true isotopic composition of our double spike using this new approach. Once the isotopic composition of the Ca double spike is established, we are able to obtain the true Ca isotopic composition of the NIST Ca standard SRM915a, ${ }^{40} \mathrm{Ca} /{ }^{44} \mathrm{Ca}=46.537 \pm 2$ $\left(2 \sigma_{\mathrm{m}}, \mathrm{n}=55\right),{ }^{42} \mathrm{Ca} /{ }^{44} \mathrm{Ca}=0.31031 \pm 1,{ }^{43} \mathrm{Ca} /{ }^{44} \mathrm{Ca}=0.06474 \pm 1$, and ${ }^{48} \mathrm{Ca} /{ }^{44} \mathrm{Ca}=0.08956 \pm 1$. Despite an offset of $1.3 \%$ in ${ }^{40} \mathrm{Ca} /{ }^{44} \mathrm{Ca}$ between our result and the previously reported value (Russell et al. 1978), our data indicate an offset of $1.89 \%$ in ${ }^{40} \mathrm{Ca} /{ }^{44} \mathrm{Ca}$ between SRM915a and seawater, entirely consistent with the published results.
\end{abstract}

Key words: Calcium isotope, Double spike, Absolute isotope ratio

Citation: Shen, J. J. S., D. C. Lee, and W. T. Liang, 2009: Absolute Ca isotopic measurement using an improved double spike technique. Terr. Atmos. Ocean. Sci., 20, 455-464, doi: 10.3319/TAO.2008.05.30.01(TT)

\section{INTRODUCTION}

Double spike technique has been widely used to determine natural isotope fractionation (Dodson 1963; Hofmann 1971; Galer 1999), however, there is yet to be a general consensus on how to obtain the isotopic composition for the double spike itself. For example, three $\mathrm{Ca}$ double spikes, ${ }^{42} \mathrm{Ca}-{ }^{48} \mathrm{Ca},{ }^{43} \mathrm{Ca}-{ }^{48} \mathrm{Ca}$, and ${ }^{42} \mathrm{Ca}-{ }^{43} \mathrm{Ca}$, have been used to study $\mathrm{Ca}$ isotope fractionation in various kinds of samples. The isotopic compositions for these double spike systems were calibrated using one of the following methods. The first method is based on the gravimetric measurement of the enriched spikes. Assuming no stoichiometric effect, Russell et al. (1978) weighed the enriched ${ }^{42} \mathrm{Ca}$ and ${ }^{48} \mathrm{Ca}$ salts before the spikes were subsequently admixed and dissolved. The double spike was then analyzed to obtain the instrumental mass fractionation for $\mathrm{Ca}$, normalized to the weighed ${ }^{42} \mathrm{Ca}^{-48} \mathrm{Ca}$ ratio, and then the same fractionation factor was used to obtain a ${ }^{42} \mathrm{Ca} /{ }^{44} \mathrm{Ca}$ of 0.31221 for natural $\mathrm{Ca}$ (Russell et al. 1978). Due to the large uncertainties in weighing, Russell et al. (1978) recommended a $\pm 1 \%$ error for their double spike isotope composition calculation. Similarly, Hart and

\footnotetext{
* Corresponding author

E-mail:mountain@earth.sinica.edu.tw
}

Zindler (1989) prepared a ${ }^{40} \mathrm{Ca}-{ }^{44} \mathrm{Ca}$ double spike and estimated that they could determine the $\mathrm{Ca}$ isotopic ratio with a precision of about $\pm 0.7 \%$, approximately an order of magnitude better than that of Russell et al. (1978).

Instead of measuring the double spike independently, several groups used the ${ }^{42} \mathrm{Ca} /{ }^{44} \mathrm{Ca}$ of 0.31221 for natural $\mathrm{Ca}$ (Russell et al. 1978) to calibrate each spike individually, and then mixed the two spikes to achieve their own double spike. Consequently, the results from these laboratories (Russell et al. 1978; Skulan et al. 1997; Zhu and Macdougall 1998; De La Rocha and DePaolo 2000; Heuser et al. 2002; Gopalan et al. 2006) are self-consistent with that of Russell et al. (1978).

The third method was based on the total evaporation technique. Using this method, Schmitt et al. (2001) determined the isotopic composition of their ${ }^{43} \mathrm{Ca}-{ }^{48} \mathrm{Ca}$ double spike, which was calibrated relative to ${ }^{42} \mathrm{Ca} /{ }^{44} \mathrm{Ca}$ ratio $=$ $0.30587 \pm 26$ of seawater. The ${ }^{42} \mathrm{Ca} /{ }^{44} \mathrm{Ca}$ of seawater was also determined from a total evaporation experiment (Schmitt et al. 2001).

Due to the large weighing errors (Russell et al. 1978), the ${ }^{42} \mathrm{Ca} /{ }^{44} \mathrm{Ca}=0.31221$ for natural $\mathrm{Ca}$ could be relatively imprecise and inaccurate. Nevertheless, with the exception 
of the total evaporation method, the isotopic compositions of the double spikes for the other groups were all calibrated relative to ${ }^{42} \mathrm{Ca} /{ }^{44} \mathrm{Ca}=0.31221$. Consequently, the accuracy of the isotopic composition of all these $\mathrm{Ca}$ double spikes should be comparable to $c a \pm 1 \%$ (Russell et al. 1978). However, because of the self-consistent for all the measurements, the precision of their $\mathrm{Ca}$ isotopic measurements should not be affected. Moreover, since all the TIMS double spike $\mathrm{Ca}$ results were measured relative to the same international standard SRM915a, knowing the absolute Ca isotopic composition of their double spikes was not essential for the study of natural $\mathrm{Ca}$ isotope fractionation. Nonetheless, knowing the absolute $\mathrm{Ca}$ isotopic composition of the double spike and the natural samples will help by eliminating the need for lengthy inter-laboratory cross-calibrations in order to set up a new double spike and related experimental protocols. Furthermore, knowing the true $\mathrm{Ca}$ isotopic composition will be critical in studies of small nucleosynthetic effects on $\mathrm{Ca}$ isotopes in primitive meteorites (Völkening and Papanastassiou 1989).

In this study, we present a new vector analytical method to obtain the absolute isotopic compositions for our ${ }^{42} \mathrm{Ca}-{ }^{48} \mathrm{Ca}$ double spike. In contrast to previous studies, this new method does not require normalization to a set isotopic ratio, e.g. ${ }^{42} \mathrm{Ca} /{ }^{44} \mathrm{Ca}=0.31221$, in order to cross-calibrate with the results of other laboratories. Lastly, since absolute $\mathrm{Ca}$ isotopic compositions for natural samples can be obtained with this new method, inter-laboratory reference standard and cross-calibration of double spikes will no longer be necessary.

\section{THEORY OF THE DOUBLE SPIKE METHOD}

As a first order approximation, we have assumed that both instrumental and natural mass-dependent fractionation follow a straight line. A three-dimensional data reduction procedure similar to that described by Galer (1999) has been adapted in this study. The relationships between the natural sample, the mixture, and the spike itself are best shown in a 3-D plot of ${ }^{40} \mathrm{Ca} /{ }^{48} \mathrm{Ca}$ vs. ${ }^{42} \mathrm{Ca} /{ }^{48} \mathrm{Ca}$ vs. ${ }^{44} \mathrm{Ca} /{ }^{48} \mathrm{Ca}$ (Fig. 1). The "true" isotopic compositions of the normal, mixture, and spike are shown as N, M, and S, respectively. The vectors $\boldsymbol{f} \mathrm{n}$ and $\boldsymbol{f} \mathrm{m}$ represent the theoretical fractionation lines of TIMS measurements for normal and spiked samples, respectively. In principle, $f \mathrm{n}$ and $\boldsymbol{f m}$ can be defined by fitting a straight line through the repeated measurements for natural and spiked samples, as shown in Fig. 1. In theory, the "true" isotopic compositions for $\mathrm{N}, \mathrm{M}$, and $\mathrm{S}$ should all lie on a straight line in Fig. 1 (Galer 1999). Despite that the actual positions of the natural and spiked samples, $\mathrm{N}$ and $\mathrm{M}$, are not known in the beginning, they should lie on the straight lines defined by the vectors $f \mathrm{n}$ and $\boldsymbol{f m}$, respectively. As a result, two planes, $\boldsymbol{P}$ and $\boldsymbol{P m}$, can be defined through combining the spike (S) and the two vectors, $\boldsymbol{f}$ n and $\boldsymbol{f m}$ (Fig. 1). Since both $\boldsymbol{P n}$ and $\boldsymbol{P}$ m share a common point S, and N, M, and S are all collinear, the line intersecting by $\boldsymbol{P n}$ and $\boldsymbol{P m}$ should thus reflect the true N-M-S mixing line (Fig. 1). Consequently, the "true" isotopic composition of $\mathrm{N}$ can be easily established since it is the intercept between the N-M-S line and $\boldsymbol{f n}$, given that the "true" isotopic composition of $\mathrm{S}$ is known (Galer 1999).

\section{MODULAR MODEL FROM DOUBLE SPIKE TECHNIQUE TO SOLVE ABSOLUTE ISOTOPIC RATIO FOR DOUBLE SPIKE}

In principle, it is possible to obtain the absolute isotopic composition of the spike by reversing the above procedures if the $\mathrm{Ca}$ isotopic composition of the natural sample is known. However, the absolute isotopic composition of $\mathrm{Ca}$ normally obtained assuming ${ }^{42} \mathrm{Ca} /{ }^{44} \mathrm{Ca}=0.31221$, should, in theory, also inherit the large, $c a \pm 1 \%$, weighing errors (Russell et al. 1978). As a result, the accuracy of the absolute isotopic composition of the spike determined using such an approach might be questionable. Since most $\mathrm{Ca}$ isotopic data are reported relative to a known isotopic standard such as the NIST SRM915a, getting accurate absolute isotopic data has become less critical. As for the precision of the data, they are largely determined by the precision of the isotopic measurement, provided that spiking and isotopic measurement are done exactly for both the spike calibration and sample analysis. Nonetheless, an independent assessment of the absolute isotopic composition of the spike, and subsequently the natural samples will minimize the overall uncer-

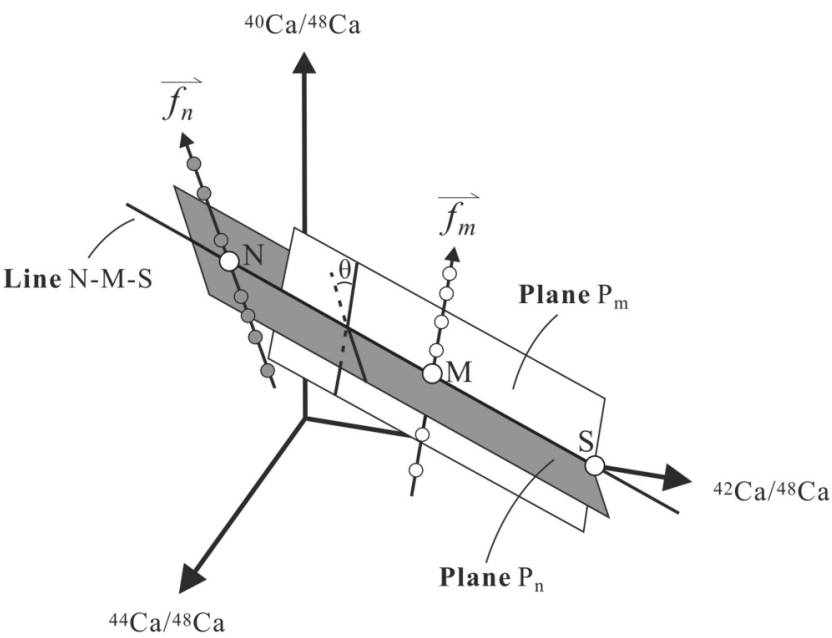

Fig. 1. 3D graphical representation after Galer (1999), illustrating the relationships between the isotopic composition of normal (unspiked) $\mathrm{N}$, mixture $\mathrm{M}$, and the spike $\mathrm{S}$ for the Ca double-spike technique. The points $\mathrm{N}, \mathrm{M}$, and $\mathrm{S}$ correspond to the "true" isotopic compositions of the normal, mixture and the spike, respectively. The vectors $f \mathrm{n}$ and $\mathrm{fm}$ are mass fractionation lines passing through the points $\mathrm{N}$ and $\mathrm{M}$, respectively. The plane $P \mathrm{n}$ is defined by $f \mathrm{pn}$ (normal vector of $\boldsymbol{f n}$; not shown) and point $S$, and similarly the plane $P \mathrm{~m}$ is defined by $\boldsymbol{f p m}$ (normal vector of $\boldsymbol{f} \mathrm{m}$; not shown) and point $\mathrm{S}$. The angle of intersection of the planes $\boldsymbol{P}$ and $\boldsymbol{P} \mathrm{m}$ when viewed along the line N-M-S is shown as $\theta$. 
tainties introduced by spiking and data reduction. This is essential for high precision $\mathrm{Ca}$ isotopic measurement. Furthermore, this will provide a critical test of whether there are systematic differences between this and previous results.

Despite N, M, and S lying on a straight line, adding the third vector, $f$ s from the spike data, cannot define the mixing line ubiquitously, since there exist an infinite number of lines that can intercept with $\boldsymbol{f} \mathrm{n}, \boldsymbol{f m}$, and $\boldsymbol{f}$ s in a 3D diagram. However, it turns out that by adding a fourth point, and hence a total of four vectors, we can define the mixing line ubiquitously. By adding a second mixture, we now have the normal (N), two mixtures (M1 and M2), and the spike (S), and again, these four points should all lie on a straight line. Similarly, the four vectors, $\boldsymbol{f} \mathrm{n}, \boldsymbol{f} \mathrm{s}, \boldsymbol{f m} 1$, and $\boldsymbol{f m} 2$, are defined by fitting through the isotopic data for normal, spike, mixture-1, and mixture-2, respectively (Fig. 2). In theory, there exists only one line that can intercept with $f \mathrm{n}, f \mathrm{~m} 1$, $\boldsymbol{f m} 2$, and $\boldsymbol{f} \mathrm{s}$, simultaneously. Given that $\mathrm{N}, \mathrm{M} 1, \mathrm{M} 2$, and $\mathrm{S}$ should be collinear, the line intercepting $f \mathrm{n}, \boldsymbol{f m} 1, \boldsymbol{f m} 2$, and $f$ s must be the true mixing line of N-M1-M2-S (Fig. 2). The "true" isotopic composition of the spike, $\mathrm{S}$, can thus be easily determined since it is the point where the N-M1-M2-S line intercepts $\boldsymbol{f}$ s (Fig. 2). It is quite clear that we can successfully obtain the true isotopic compositions of our double spike without the need of a reference ratio, as was the case in previous studies.

\section{VECTOR ANALYTIC METHOD}

Data reduction is done using a program written with the commercial software Matlab, and a brief description of how the calculations were done are given as follows. Assuming the isotopic composition of the spike, $\mathrm{S}$, is known, the program starts by combining vector $\boldsymbol{f} n$ and point $S$ to define the normal vector $\boldsymbol{f}$ pn for plane $\boldsymbol{P n}$, and vice versa for $\boldsymbol{f} \mathrm{pm}$ and $\boldsymbol{P}$ m (Fig. 1). After the normal vectors of $\boldsymbol{f} \mathrm{pn}$ and $\boldsymbol{f} \mathrm{pm}$ are defined, the vector of N-M-S line $(\boldsymbol{f} n-\mathrm{m}-\mathrm{s})$ is subsequently defined by crossing these two normal vectors $(f \mathrm{pn} \times f \mathrm{pm})$. Since the vector $f n-m-s$ should pass through the $S$ point, the equation of N-M-S line can be then defined. Consequently, the original isotopic ratio for the natural sample $(\mathrm{N})$ can be obtained by the interception between the equation of N-M-S line and $f$ n.

After the equation of N-M-S line is defined, we can then rotate and shift Fig. 1 to allow the new $\mathrm{Z}$ axis as the N-M-S line, and the new $\mathrm{X}$ axis as the projection of $\boldsymbol{P}$ (Fig. 3 a). $P$ n is also shown as the open circles that coincide with the $\mathrm{X}$ axis, while $\boldsymbol{P m}$ is shown as the open squares in Fig. 3a. The angle between $\boldsymbol{P}$ and $\boldsymbol{P}$ m, $\theta$, depends on the double spike ratio and the spike to sample ratio in the mixture (Galer 1999). The point of interception in Fig. 3a is referred to as the N-M-S point.

The determination of the true isotopic ratio of the double spike is illustrated in Fig. 3b. Although $\mathrm{S}$ is unknown in the beginning, it should lie on a straight line defined by $f \mathrm{~s}$ (Fig. 2). In principle, we can use any point on $f \mathrm{~s}$, say $\mathrm{S}_{\mathrm{i}}$, and combine it with $\boldsymbol{f} \mathrm{n}$ and $\boldsymbol{f m} 1$ to define a N-M1-S $\mathrm{S}_{\mathrm{i}}$ point in Fig. 3b, and vice versa for an N-M2-S $\mathrm{S}_{\mathrm{i}}$ point. Since N, M1, $\mathrm{M} 2$, and S should be collinear, N-M1-S and N-M2-S should be projected on the same point in Fig. 3b. This suggests that $\mathrm{S}_{\mathrm{i}}$ is not the true " $\mathrm{S}$ " if there is an offset between N-M1-S and N-M2-S $\mathrm{S}_{\mathrm{i}}$ Fig. 3b. An iterative process is then used to find the true isotopic composition of the double spike $\mathrm{S}$.

\section{MASS SPECTROMETRY}

Samples were analyzed by double filament technique using TRITON of Thermo Finnigan, at IES. Approximately $1 \sim 2 \mu \mathrm{g}$ of $\mathrm{Ca}$ in nitrite form were loaded on Re filament, and then heated in air until the filament was glowing. For each isotopic measurement, the ion current for ${ }^{40} \mathrm{Ca}$ was set to $3.7 \times 10^{-10}, 2 \times 10^{-10}$, and $1.5 \times 10^{-11}$ for normal, mixture, and spike, respectively. The working temperature for the ionization filament was $\sim 1400^{\circ} \mathrm{C}$, and the working current for the vaporization filament is $350-500 \mathrm{~mA}$. Cup configuration is shown in Table 1 . Two analytical sequences were required because the mass dispersion range in TRITON is not sufficient to cover the $\mathrm{Ca}$ isotopes from ${ }^{40} \mathrm{Ca}$ to ${ }^{48} \mathrm{Ca}$. Mass 40, 41, 42, 43, and 44 are measured in the first sequence, while mass 44 and 48 are measured in the second sequence. A total of 6 faraday cups were used, and each cup was assigned to a specific mass to avoid potential non-linear mass dispersion effect from dramatic changes in signal intensity. The ${ }^{41} \mathrm{~K}$ was monitored to be always less than $1.5 \times$ $10^{-14} \mathrm{~A}$, and thus interference from $\mathrm{K}$ at mass 40 is negligible.

Virtual amplifier mode was used throughout the experiment, in order to minimize the instability of inter-channel calibration. The integration times are also shown in Table 1.

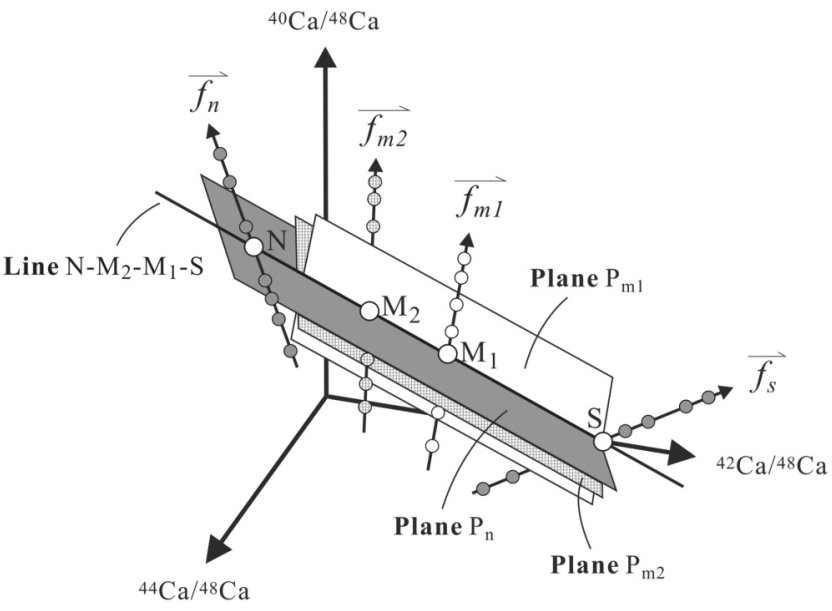

Fig. 2. 3D graph for a modified double-spike technique from Fig. 1. The four vectors $(f \mathrm{n}, \boldsymbol{f m} 1, f \mathrm{~m} 2$, and $\boldsymbol{f} \mathrm{s})$ and three planes $(\boldsymbol{P} \mathrm{n}, \boldsymbol{P m} 1$, and $\boldsymbol{P} \mathrm{m} 2)$ are defined the same as those in Fig. 1. 
(a)

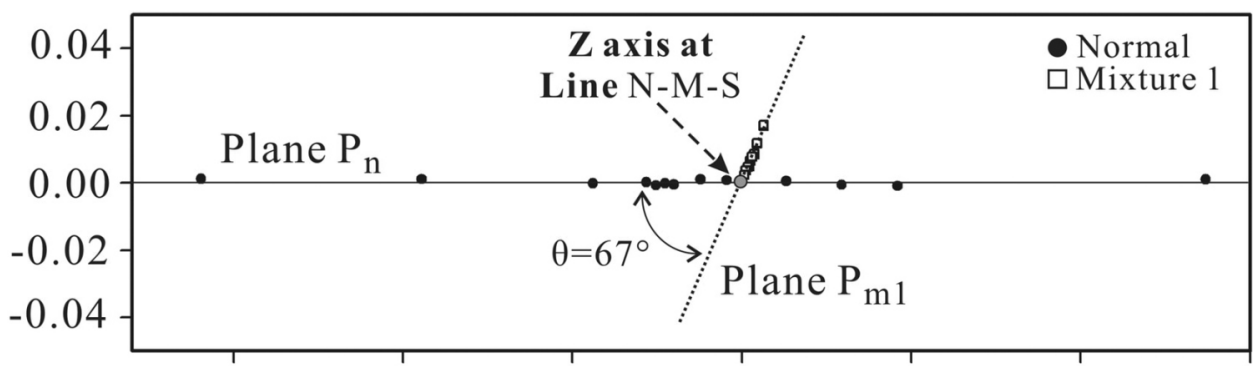

(b)

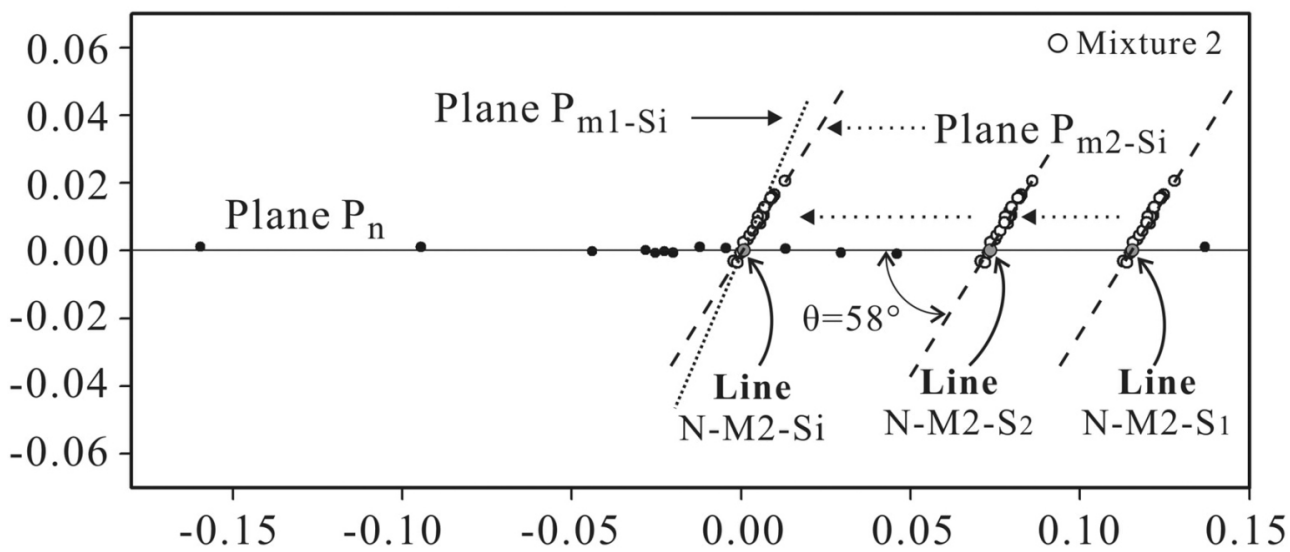

Fig. 3. Rotating and shifting the 3D diagrams from Fig. 1 (a) and Fig. 2 (b) such that the new $\mathrm{Z}$ axis coincides with line N-M-S and the new X axis coincides with plane $\boldsymbol{P}$ n. $\theta$ is the intersection angle between the planes $\boldsymbol{P}$ and $\boldsymbol{P} \mathrm{m}$ when viewed along the line N-M-S. Fig. $3 \mathrm{~b}$ shows the iteration process

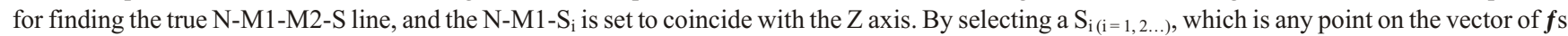
in Fig. 2, we can subsequently fix the N-M1-S and N-M2-S points in Fig. 3b. The process is repeated until we find $\mathrm{S}_{\mathrm{i}}$ where N-M1-S $\mathrm{S}_{\mathrm{i}}$ overlaps $\mathrm{N}-\mathrm{M} 2-\mathrm{S}_{\mathrm{i}}$ in Fig. $3 \mathrm{~b}$; the point $\mathrm{S}_{\mathrm{i}}$ is thus the true isotopic ratio for the double spike.

Table 1. The cup configuration, integration time, and general signal intensities for Ca isotope measurement in Thermo Finnigan TRITON mass spectrometer.

\begin{tabular}{lccccccccc}
\hline Cup & L3 & L2 & L1 & Ax & H1 & H2 & H3 & Idle Time & Integration Time \\
\hline Step 1 & ${ }^{40} \mathrm{Ca}$ & ${ }^{41} \mathrm{~K}$ & ${ }^{42} \mathrm{Ca}$ & 42.5 & ${ }^{43} \mathrm{Ca}$ & ${ }^{44} \mathrm{Ca}$ & & $3 \mathrm{sec}$ & $8 \mathrm{sec}$ \\
Step 2 & & ${ }^{44} \mathrm{Ca}$ & & 45.5 & & & ${ }^{48} \mathrm{Ca}$ & $3 \mathrm{sec}$ & $8 \mathrm{sec}$ \\
Normal & $37 \mathrm{~V}$ & $800 \mathrm{mV}$ & $0.24 \mathrm{~V}$ & & $50 \mathrm{mV}$ & $800 \mathrm{mV}$ & $72 \mathrm{mV}$ & & \\
Mixture & $20 \mathrm{~V}$ & $400 \mathrm{mV}$ & $2.2 \mathrm{~V}$ & & $36 \mathrm{mV}$ & $400 \mathrm{mV}$ & $1.7 \mathrm{~V}$ & & \\
Spike & $1.5 \mathrm{~V}$ & $200 \mathrm{mV}$ & $20 \mathrm{~V}$ & & $90 \mathrm{mV}$ & $200 \mathrm{mV}$ & $15.3 \mathrm{~V}$ & & \\
\hline
\end{tabular}

A total of 270 ratios per measurement was needed for unspiked samples, in order to acquire $\sim 9.7 \times 10^{9}$ ions for ${ }^{48} \mathrm{Ca}$, the least smallest $\mathrm{Ca}$ isotope in this experiment such that theoretically a long term statistical uncertainty of $10 \mathrm{ppm}$ can be achieved. As for the spiked samples, 135 ratios per measurement were enough to achieve the required precision.

Approximately $0.1 \mathrm{ml}$ of seawater was spiked and purified by passing through a cation exchange column composed of $\sim 1 \mathrm{ml}$ of AG 50W-X8 $200-400$ mesh resin. The alkalis were removed by eluting with $30 \mathrm{ml}$ of $0.5 \mathrm{~N} \mathrm{HCl}$, and $\mathrm{Ca}$ was subsequently eluted with additional $8 \mathrm{ml}$ of $4 \mathrm{~N} \mathrm{HCl}$. In order to convert the sample to nitrate form, it was re-dis- solved with $0.5 \mathrm{ml}$ of concentrated $\mathrm{HNO}_{3}$ and dried twice before it was analyzed.

\section{RESULTS AND DISCUSSION}

Despite it being possible to independently constrain the true isotopic composition for our double spike, it is still crucial to have an optimal double spike ratio, as well as an optimal sample-to-spike mixing ratio in order to minimize the uncertainties introduced during spike de-convolution calculations. Different spike ratios will result in different geometry of the $\boldsymbol{P}$ and $\boldsymbol{P}$ m planes in Fig. 1. In principle, in or- 
der to better define the N-M-S line, the angle of intersection $\theta$ should be large and close to $90^{\circ}$ (Figs. 1, 3a) (Galer 1999). Conversely, if $\theta$ is approaching zero, the intersection line will not be defined very precisely. Illustrated in Fig. 4 are the effects of varying the sample-to-spike and the spike ratios. Each curve is plotted for a discrete value of Q, which is the proportion of ${ }^{48} \mathrm{Ca}$ (Fig. 4a) and ${ }^{42} \mathrm{Ca}$ (Fig. 4b) of the spike in the mixture, with the values of 0 and 1 representing pure normal and pure spike in the mixture, respectively.

It is shown in Fig. 4 that the intersection angle $\theta$ remains $<45^{\circ}$ for all $\mathrm{Q}$ values less than or equal to 0.7 . This implies that in order to better define the N-M-S line, most of the ${ }^{48} \mathrm{Ca}$ and ${ }^{42} \mathrm{Ca}$ in the mixture should come from the spike. Consequently, the optimal double spike isotopic composition $\left({ }^{42} \mathrm{Ca} /{ }^{48} \mathrm{Ca}\right)$ lies around 1.3 , which is a compromise between Figs. $4 \mathrm{a}$ and $\mathrm{b}$. Evidently, the intersection angle $\theta$ between $\boldsymbol{P}$ and $\boldsymbol{P} \mathrm{m} 1$ and $\boldsymbol{P}$ and $\boldsymbol{P m} 2$ is $67^{\circ}$ and $58^{\circ}$, respectively.

\subsection{Fractionation Law and the "True" Isotopic Composition}

In this study, vectors are defined as the directions of mass fractionation for $\mathrm{Ca}$ isotopic measurements, and they are all straight lines. This approach involves the use of a simple linear regression law, instead of the commonly used exponential law, in which fractionation is described as a curve (Russell et al. 1978), although exponential law remains insufficient to fully accommodate the mass fractionation of $\mathrm{Ca}$ (Hart and Zindler 1989). Jungck et al. (1984) proposed a modified exponential law, because they observed some significant and systematic drifts in $\mathrm{Ca}$ isotopic data. Furthermore, Gopalan et al. (2006) used a ${ }^{42} \mathrm{Ca}-{ }^{43} \mathrm{Ca}$ double spike instead of a more widely adopted ${ }^{42} \mathrm{Ca}-{ }^{48} \mathrm{Ca}$ double spike for their $\mathrm{Ca}$ isotopic measurements, owing to a better match between the exponential law and the $\mathrm{Ca}$ isotopic fractionation for a smaller mass range. Different from previous studies, we used an empirical 3D fitting method to define the mass fractionation of Ca in this study (Fig. 5). By default, this empirical 3D fitting produces a straight line that can be easily adapted in the subsequent vector analytic calculation. Despite exponential law having been widely used to correct for mass fractionation during isotopic measurement, it remains an empirical approach, and precision and accuracy for a given isotopic ratio tends to degrade when mass difference increases (Jungck et al. 1984; Hart and Zindler 1989; Gopalan et al. 2006).

In order to assess the difference between the exponential law and our empirical 3D line fitting method, we normalized the raw data to the "true" ${ }^{42} \mathrm{Ca} /{ }^{44} \mathrm{Ca}$ ratio obtained from this study for each set of data, including the normal, the mixtures, and the spike, using both linear and exponential laws, and the results are shown in Fig. 5. As illustrated in Fig. 5b, there is little difference between the data normalized by linear law, identical to our empirical 3D line fitting calculation, and that analyzed by exponential law for each single run, nor is there much difference in the grand mean of every set of samples. In fact, the linear and exponential law normalized grand means are within $50 \mathrm{ppm}$ of each other for all samples. This result is comparable to or within analytical uncertainties for the determination of ${ }^{40} \mathrm{Ca} /{ }^{44} \mathrm{Ca}$ (Fig. 5b). This suggests that within the spread of our data $(\leq \pm 0.5 \%$ /amu, Fig. 5a), linear regression yields similar results to exponential regression. Furthermore, ${ }^{40} \mathrm{Ca} /{ }^{44} \mathrm{Ca}$ obtained for each data set lies within the spread of the raw data (Fig. 5a) pro- (a)

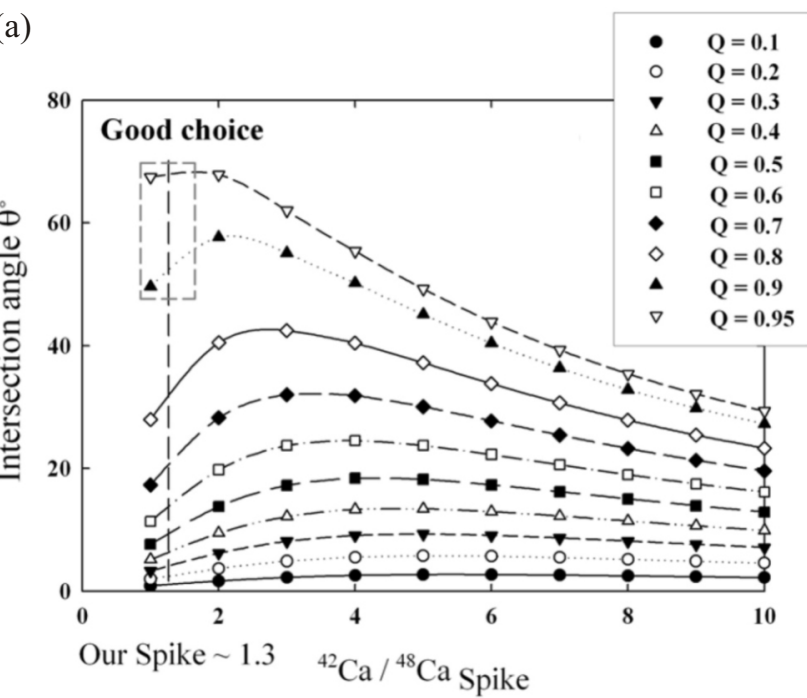

(b)

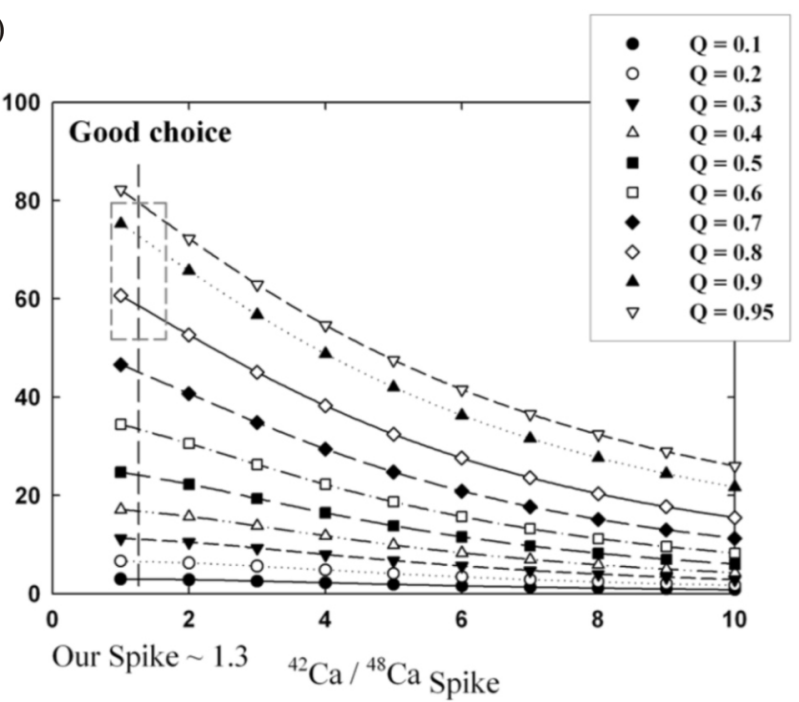

Fig. 4. Intersection angle $\theta$ between the two planes $\boldsymbol{P}$ and $\boldsymbol{P m}$ (Fig. 1) is plotted against the ${ }^{42} \mathrm{Ca} /{ }^{48} \mathrm{Ca}$ ratio of the double spike $\mathrm{S}$ shown in Fig. 1. Each curve is designated for a specific value of $\mathrm{Q}$, which is the proportion of ${ }^{48} \mathrm{Ca}$ in the mixture $\mathrm{M}$ that comes from the spike (a), and the proportion of ${ }^{42} \mathrm{Ca}$ in the mixture $\mathrm{M}$ that comes from the spike (b). The optimal ${ }^{42} \mathrm{Ca} /{ }^{48} \mathrm{Ca}$ ratio is around 1.3 , a compromise to maximize both ${ }^{42} \mathrm{Ca}$ and ${ }^{48} \mathrm{Ca}$ spikes. The dashed line boxes indicate the mixtures used in this study. 


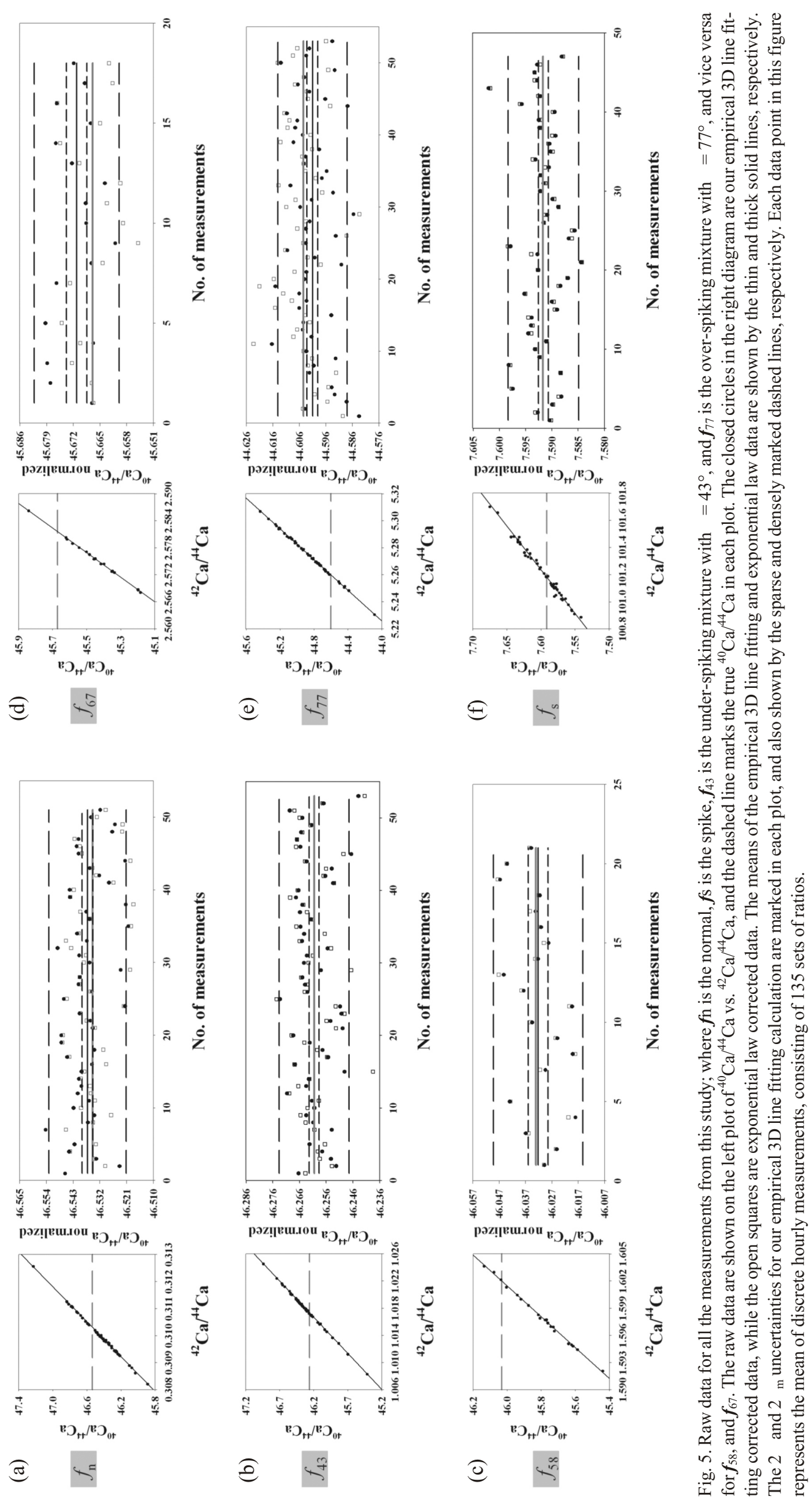


viding further support to the use of this empirical 3D line fitting method.

Overall mass fractionation in each individual measurement, including 135 sets of raw data, is noticeably smaller $(\sim 0.6 \%$ /amu $)$ than the overall mass fractionation of the 10 to 20 measurements $(\sim 5 \%$ /amu) that are necessary for a statistically significant vector fitting. Strictly speaking, our empirical line fitting approach is quite similar to the samplestandard bracketing technique widely used in ICP-MS isotopic measurements, with a linear fit to both the standards and the samples to decipher the isotopic differences between them. Lastly, an empirical fitting line to correct for mass fractionations has been applied to La and B isotopic measurements on TIMS with great success (Shen et al. 1992; Shen and Yu 2003).

The results of the NIST SRM 915a and a seawater sample from the South China Sea using our vector analytical method are shown in Fig. 6, along with the literature data of the same samples for comparison (Heuser et al. 2002; Hippler et al. 2003; Schmitt et al. 2003; Fantle and DePaolo 2005; Schmitt and Stille 2005; Sime et al. 2005). In general, the data can be divided into three groups. The data from Berkeley, Bern, and Kiel are all sitting on the upper right hand side of Fig. 6, and this is because their double spikes were calibrated assuming ${ }^{42} \mathrm{Ca} /{ }^{44} \mathrm{Ca}=0.31221$ to monitor mass fractionation. Despite the same procedures used in these labs, there exists $\sim 1.3 \%$ difference among their ${ }^{40} \mathrm{Ca} /{ }^{44} \mathrm{Ca}$ ratios (Fig. 6). In contrast, the UCSD group (Zhu and MacDougall 1998) calibrated its double spike ratio to ${ }^{40} \mathrm{Ca} /{ }^{44} \mathrm{Ca}$ $=46.083$, which was a commercial ultrapure $\mathrm{CaCO}_{3}$ standard, and a mean uncorrected ${ }^{40} \mathrm{Ca} /{ }^{44} \mathrm{Ca}$ isotopic ratio was reported by Jungck et al. (1984). The UCSD data show $\sim 2.3 \%$ difference compared to those normalized to the results of Russell et al. (1978). Because of Ca's long residence time of $\sim 1$ Ma in the oceans, the Strasbourg group calibrated its double spike isotopic ratio to the ${ }^{42} \mathrm{Ca} /{ }^{44} \mathrm{Ca}(=0.30587 \pm$ 26) of seawater, derived from a total evaporation experiment, and their data sits on the lower-left hand side of Fig. 6 (Schmitt et al. 2001, 2003; Schmitt and Stille 2005). The results of the total evaporation experiment show $\sim 4.3 \%$ difference compared to those normalized to the results of Russell et al. (1978).

Different from the previous results, SRM915a and seawater data obtained in this study are plotted in between these two groups of data (Fig. 6), with ${ }^{40} \mathrm{Ca} /{ }^{44} \mathrm{Ca}=46.537 \pm 2$ $\left(2 \sigma_{\mathrm{m}}, \mathrm{n}=55\right),{ }^{42} \mathrm{Ca} /{ }^{44} \mathrm{Ca}=0.31031 \pm 1,{ }^{43} \mathrm{Ca} /{ }^{44} \mathrm{Ca}=0.06474$ \pm 1 , and ${ }^{48} \mathrm{Ca} /{ }^{44} \mathrm{Ca}=0.08956 \pm 1$. Compared to SRM915a, seawater exhibits an apparent offset of $1.89 \%$ for ${ }^{40} \mathrm{Ca} /{ }^{44} \mathrm{Ca}$ (Fig. 6), which is entirely consistent with previous studies (Heuser et al. 2002; Hippler et al. 2003; Schmitt et al. 2003; Fantle and DePaolo 2005; Schmitt and Stille 2005; Sime et al. 2005). Furthermore, our data indicate a $1.3 \%$ offset in ${ }^{40} \mathrm{Ca} /{ }^{44} \mathrm{Ca}$ for the Earth's mantle compared to the previous result (Fig. 6) (Russell et al. 1978).

\subsection{Under- and Over-Spiking}

The theory and the effects of error propagation for under- and over-spiking have been studied extensively (Dodson 1963; Cumming 1973; Galer 1999). However, since true isotopic compositions of the spike might not have been obtained in previous studies, potential errors associated with incorrect spike compositions have never been explored properly. In the case of the double spike, the main contributing factors for error magnification are the intersection angle $\theta$, the proportion of the spike in the mixture $\mathrm{Q}$, and the spread of the raw isotopic data (Galer 1999). Strictly speaking, careful spiking and mass spectrometry can minimize propagated errors associated with double spike measurement; this is also true for potential errors associated with incorrect spike compositions. This is illustrated in Fig. 7 where a fixed sample-to-spike ratio still produces highly reproducibility results for isotopic fractionation measurement of naturally occurring $\mathrm{Ca}$ even with a wrong spike isotopic ratio, however, this is no longer true for an under- or over-spiking sample (Fig. 7). Nevertheless, under- and over-spiking present no problem if the spike isotopic ratio is known. To further quantify this, an under-spiking and an over-spiking SRM915a each with a $\theta$ of $43^{\circ}$ and $77^{\circ}$ between $\boldsymbol{P}_{\mathrm{n}}$ and $\boldsymbol{P}_{\text {under }}$ and $\boldsymbol{P}_{\mathrm{n}}$ and $\boldsymbol{P}_{\text {over, }}$, respectively (Figs. 5b and e), are measured. The results show a 35 ppm shift for the under-spiking SRM915a standard, which is within the limits of analytical precision, but a $110 \mathrm{ppm}$ shift for the over-spiking SRM915a standard, which is within $4 \sigma_{\mathrm{m}}$. The slightly worse result for the overspiking sample is most likely caused by the fact that the $\boldsymbol{f}_{77}$ and $f_{\mathrm{s}}$ vectors are too close in the $3 \mathrm{D}$ diagram.

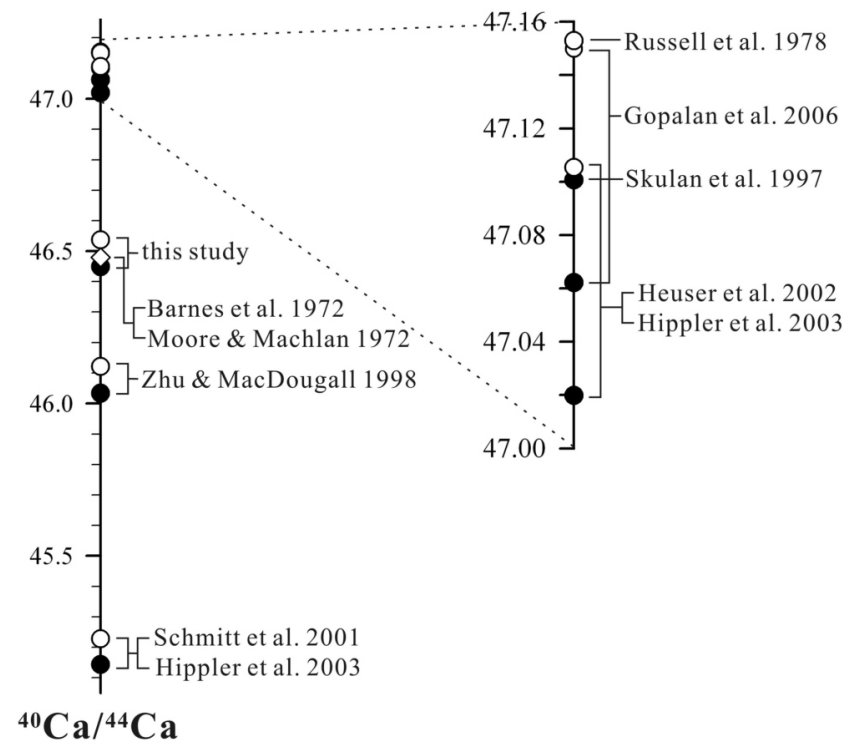

Fig. $6 .{ }^{40} \mathrm{Ca} /{ }^{44} \mathrm{Ca}$ of SRM915a and seawater for this study, as well as from other laboratories worldwide. The SRM915a data are shown as open circles, seawater data as closed circles, and SRM915 from NBS as an open diamond. 


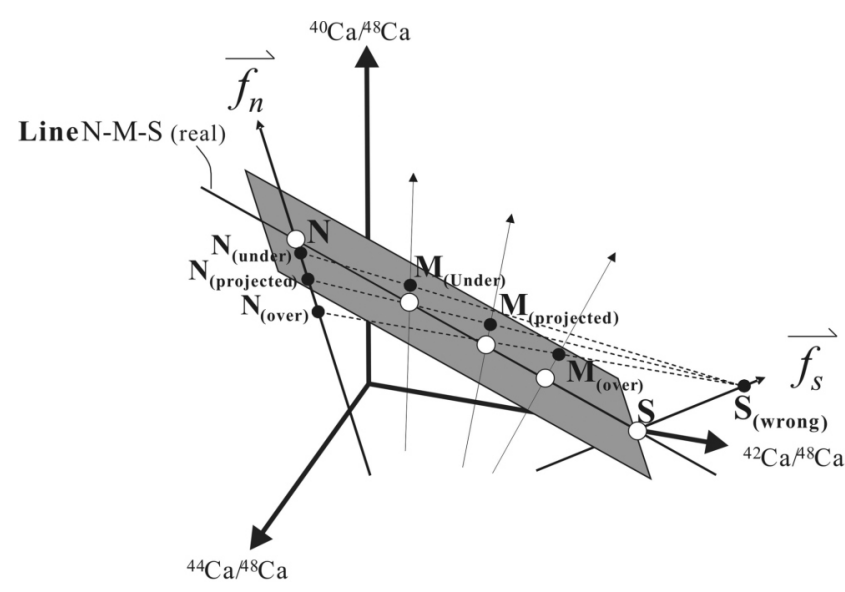

Fig. 7. As shown in the plot, a "wrong" spike ratio can still generate highly precise and reproducible results, as long as the sample-to-spike ratio is kept constant. However, under such circumstances, under- and over-spiking samples will produce wrong and irreproducible results.

\subsection{Error Estimation for the True Isotopic Ratio of the Double Spike}

The analytical errors for all the measurements are shown in Fig. 8, while the errors for all the samples are within $100 \mathrm{ppm}$, the only exception is the double spike measurement, which is slightly worse at about $\pm 0.12 \%$ o $\left(2 \sigma_{\text {mean }}\right)$ (Fig. 5f). This is probably due to the small amount of ${ }^{44} \mathrm{Ca}$ in the double spike. Figure 8 is actually a cross section of Fig. 3b, and the error bars represent the width for each vector in Fig. $3 \mathrm{~b}$. As a result, the horizontal line at $\mathrm{Y}=0$ in Fig. 8 is the same as the N-M-S line in Fig. 1, and the error bar reflects the cross section of a circular disc perpendicular to Fig. 8. As mentioned above, the true isotopic composition of the spike can be solved with four different vectors (Fig. 2). Similarly, the N-M43-M58-M67 line can be solved with four vectors, $f$ n, $\boldsymbol{f}_{43}, \boldsymbol{f}_{58}$, and $\boldsymbol{f}_{67}$, and by definition the N-M43-M58-M67 line will also pass through the $S$ point (Fig. 8). Evidently, the precision of our double spike determination has improved from 120 ppm (Fig. 5f) to 74 ppm, through solving the N-M43M58-M67 line (Fig. 8). As a result, the isotopic composition of our double spike is: ${ }^{40} \mathrm{Ca} /{ }^{44} \mathrm{Ca}=7.5916 \pm 6,{ }^{42} \mathrm{Ca} /{ }^{44} \mathrm{Ca}=$ $101.182 \pm 7$, and ${ }^{48} \mathrm{Ca} /{ }^{44} \mathrm{Ca}=76.756 \pm 6$.

It is not a critical task to obtain the "absolute" isotopic ratio of a double spike, if the purpose is only to use the natural fractionation of stable isotopes as tracers to understand geological processes. This is because modern mass spectrometry can easily distinguish the isotopic differences between a specific standard and an unknown sample with reasonable precision, with or without a correct reference ratio. Knowledge of the absolute isotopic composition of the double spike, however, becomes critical when high precision data of $0.05 \%$ or better are needed. Moreover, several different international standards for different types of samples are needed to minimize error propagation due to a spread in isotopic ratios, and all standards need to be calibrated independently. The method outlined in this study can produce the absolute isotopic composition of all samples, and hence cross-calibration with multiple standards is no longer necessary. Furthermore, this method can be applied not only to $\mathrm{Ca}$, but also to any element with 4 isotopes or more. For example, this technique is particularly useful for the $\mathrm{Pb}$ isotope system, which has only one isotope of constant abundance. This technique can allow for precise determination of initial $\mathrm{Pb}$ isotopic composition of different samples containing radiogenic or common $\mathrm{Pb}$. In addition, it can accurately measure the initial $\mathrm{Pb}$ isotopic composition of the solar system and subsequently the geochron. As a consequence of this advance better precision and accuracy is now possible when utilizing the $\mathrm{Pb}$ isotope system as a tracer or in age dating.

\section{CONCLUSION}

The double-spike technique has been widely used to obtain precise isotopic data for elements lacking a pair of stable isotopes with constant abundance to monitor mass fractionation during isotopic analysis. Examples of this are $\mathrm{Pb}$, as well as other naturally occurring isotopic fractionations such as those for $\mathrm{Ca}, \mathrm{Fe}$, and Mo. Although the principles for setting up a double spike are well established, the importance of obtaining the true isotopic composition of the double spike has often been overlooked. This is particularly important for high precision stable isotope analysis, since slight offsets in the isotopic composition of the double spike may introduce error larger than analytical uncertainty, if the sample-to-spike ratio has not been kept constant. Another

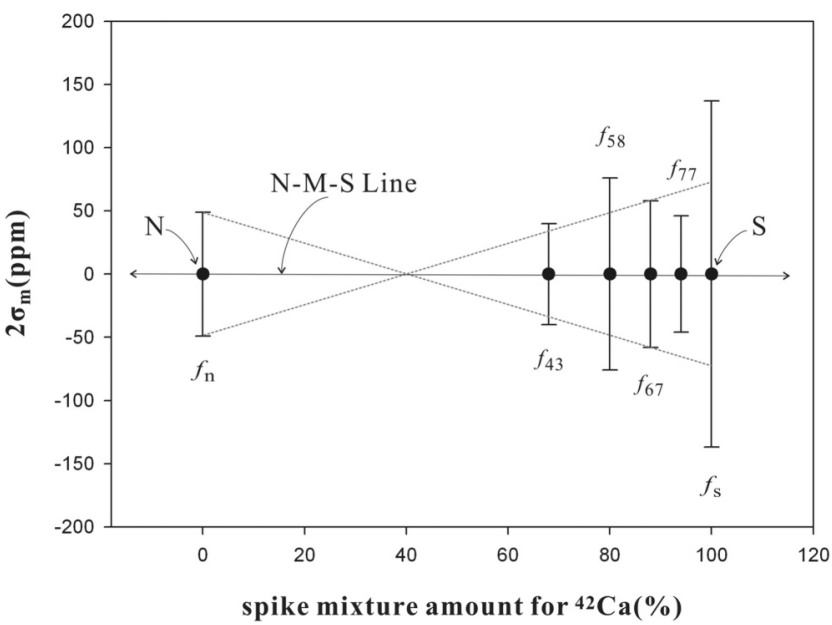

Fig. 8. A plot of the sample-to-spike ratio for ${ }^{42} \mathrm{Ca}$ vs. $2 \sigma_{\mathrm{m}}$ uncertainty for all the samples. The $2 \sigma_{\mathrm{m}}$ for each sample is represented by the width of each vector (Fig. 3b). The N-M-S line can also be solved using 4 independent vectors, $f \mathrm{n}, \boldsymbol{f}_{43}, \boldsymbol{f}_{58}$, and $\boldsymbol{f}_{67}$, and by definition this line will pass through the spike S. Consequently, the uncertainty associated with spike composition is noticeably improved compared to the analytical $2 \sigma_{\mathrm{m}}$ uncertainty. 
obvious application is to provide better estimates of atomic weights. However, since all samples experience natural mass fractionation, it is unlikely that one would obtain a sample (or standard) of any element that is truly of unfractionated isotopic composition. Nevertheless, it is possible to obtain the absolute isotopic composition of specific standards for elements of interest, e.g., SRM915a for Ca. However, since ${ }^{46} \mathrm{Ca}$ was not measured in this study, it is not possible to provide the atomic weight of Ca for SRM 915a.

With improved mass spectrometry and knowing the exact isotopic composition of our ${ }^{42} \mathrm{Ca}-{ }^{48} \mathrm{Ca}$ spike, we are able to achieve a precision of $0.05 \% 0\left(2 \sigma_{\text {mean }}\right)$ or better on a routine basis for ${ }^{40} \mathrm{Ca} /{ }^{44} \mathrm{Ca}$. Since our method produces absolute $\mathrm{Ca}$ isotopic composition for all samples, as well as the Ca double-spike itself simultaneously, cross-calibration with multiple standards are no longer necessary.

Lastly, this method can be applied not only to the Ca isotope, but also to any isotope system with 4 isotopes or more, e.g., $\mathrm{Ti}, \mathrm{Cr}, \mathrm{Fe}, \mathrm{Ni}, \mathrm{Zn}, \mathrm{Mo}, \mathrm{Ba}$, and $\mathrm{Pb}$, and greatly enhances the use of isotopes as tracers and in age dating.

Acknowledgements The authors would like to thank W. Y. Hsu and Y. H. Lai for their assistance in TIMS measurements. Discussion with K. Y. Wei and S. T. Shan have been very helpful. This work is funded by National Science Council (NSC) to J. J. S. Shen.

\section{REFERENCES}

Barnes, I. L., B. S. Carpenter, E. L. Garner, J. W. Gramlich, E. C. Kuehner, L. A. Machlan, E. J. Maienthal, J. R. Moody, L. J. Moore, T. J. Murphy, P. J. Paulsen, K. M. Sappenfield, and W. R. Shields, 1972: Isotopic abundance ratios and concentrations of selected elements in Apollo 14 samples. Proc. Third Lunar Sci. Conf., Geochim. Cosmochim. Acta Suppl., 3, 1465-1472.

Cumming, G. L., 1973: Propagation of experimental errors in lead isotope ratio measurements using the double spike method. Chem. Geol., 11, 157-165, doi: 10.1016/00092541(73)90014-4. [Link]

De La Rocha, C. L. and D. J. DePaolo, 2000: Isotopic evidence for variations in the marine calcium cycle over the Cenozoic. Science, 289, 1176-1178, doi: 10.1126/science.289. 5482.1176. [Link]

Dodson, M. H., 1963: A theoretical study of the use of internal standards for precise isotopic analysis by the surface ionization technique: Part I- General first-order algebraic solutions. J. Sci. Instrum., 40, 289-295, doi: 10.1088/09507671/40/6/307. [Link

Fantle, M. S. and D. J. DePaolo, 2005: Variations in the marine Ca cycle over the past 20 million years. Earth Planet. Sci. Lett., 237, 102-117, doi: 10.1016/j.eps1.2005.06.024. [Link]

Galer, S. J. C., 1999: Optimal double and triple spiking for high precision lead isotopic measurement. Chem. Geol., 157, 255-274, doi: 10.1016/S0009-2541(98)00203-4. [Link]
Gopalan, K., D. Macdougall, and C. Macisaac, 2006: Evaluation of a ${ }^{42} \mathrm{Ca}-{ }^{43} \mathrm{Ca}$ double-spike for high precision $\mathrm{Ca}$ isotope analysis. Int. J. Mass Spectrom., 248, 9-16, doi: 10.1016/j.ijms.2005.09.009. [Link]

Hart, S. R. and A. Zindler, 1989: Isotope fractionation laws: A test using calcium. Intl. J. Mass Spectrom. Ion. Process., 89, 287-301, doi: 10.1016/0168-1176(89)83065-4. [Link]

Heuser, A., A. Eisenhauer, N. Gussone, B. Bock, B. T. Hansen, and T. F. Nägler, 2002: Measurement of calcium isotopes $\left(\delta^{44} \mathrm{Ca}\right)$ using a multicollector TIMS technique. Int. J. Mass Spectrom., 220, 385-397, doi: 10.1016/S1387-3806(02) 00838-2. [Link]

Hippler, D., A. D. Schmitt, N. Gussone, A. Heuser, P. Stille, A. Eisenhauer, and T. F. Nägler, 2003: Calcium isotopic composition of various reference materials and seawater. Geostand. Geoanal. Res., 27, 13-19, doi: 10.1111/j.1751-908X. 2003.tb00709.x. [Link]

Hofmann, A., 1971: Fractionation corrections for mixed-isotope spikes of Sr, K, and Pb. Earth Planet. Sci. Lett., 10, 397-402, doi: 10.1016/0012-821X(71)90087-2. [Link]

Jungck, M. H. A., T. Shimamura, and G. W. Lugmair, 1984: Ca isotope variations in A llende. Geochim. Cosmochim. Acta, 48, 2651-2658, doi: 10.1016/0016-7037(84)90313-2. [Link]

Moore, L. J. and L. A. Machlan, 1972: High accuracy determination of calcium in blood serum by Isotope dilution mass spectrometry. Anal. Chem., 44, 2291-2296, doi: 10.1021/ ac60322a014. [Link]

Russell, W. A., D. A. Papanastassiou, and T. A. Tombrello, 1978: Ca isotope fractionation on the earth and other solar system materials. Geochim. Cosmochim. Acta, 42, 10751090, doi: 10.1016/0016-7037(78)90105-9. [Link]

Schmitt, A.-D. and P. Stille, 2005: The source of calcium in wet atmospheric deposits: Ca-Sr isotope evidence. Geochim. Cosmochim. Acta, 69, 3463-3468, doi: 10.1016/j.gca.2004. 11.010. [Link]

Schmitt, A.-D., G. Bracke, P. Stille, and B. Kiefel, 2001: The calcium isotope composition of modern seawater determined by thermal ionization mass spectrometry. Geostand. Geoanal. Res., 25, 267-275, doi: 10.1111/j.1751-908X. 2001.tb00602.x. [Link]

Schmitt, A.-D., F. Chabaux, and P. Stille, 2003: The calcium riverine and hydrothermal isotopic fluxes and the oceanic calcium mass balance. Earth Planet. Sci. Lett., 213, 503518, doi: 10.1016/S0012-821X(03)00341-8. [Link]

Shen, J. J.-S. and C. F. You, 2003: A 10-fold improvement in the precision of boron isotopic analysis by negative thermal ionization mass spectrometry. Anal. Chem., 75, 1972-1977, doi: 10.1021/ac020589f. [Link]

Shen, J. J.-S., T. Lee, and C. T. Chang, 1992: Detecting small isotopic shifts in two-isotopic elements using thermal ionization mass spectrometry. Anal. Chem., 64, 2216-2220, doi: 10.1021/ac00043a006. [Link]

Sime, N. G., C. L. De La Rocha, and A. Galy, 2005: Negligible temperature dependence of calcium isotope fractionation in 12 species of planktonic foraminifera. Earth Planet. Sci. 
Lett., 232, 51-66, doi: 10.1016/j.epsl.2005.01.011. [Link]

Skulan, J., D. J. DePaolo, and T. L. Owens, 1997: Biological control of calcium isotopic abundances in the global calcium cycle. Geochim. Cosmochim. Acta, 61, 2505-2510, doi: 10.1016/S0016-7037(97)00047-1. [Link]

Völkening, J. and D. A. Papanastassiou, 1989: Iron isotope ano- malies. Astrophy. J., 347, L43-L46, doi: 10.1086/185603. [Link]

Zhu P. and J. D. Macdougall, 1998: Calcium isotopes in the marine environment and oceanic calcium cycle. Geochim. Cosmochim. Acta, 62, 1691-1698, doi: 10.1016/S00167037(98)00110-0. [Link] 